\title{
Two cases of renal cell cancer during immunobiologic therapy for psoriasis
}

\author{
Fabiana Palmieri Zarur ${ }^{1}$ \\ Monique Samy Pamplona Mafort ${ }^{1}$ \\ João Carlos Regazzi Avelleira ${ }^{1}$
}

\author{
Luiza Ferreira Vieira d'Almeida ${ }^{1}$ \\ Paula Regazzi de Gusmão ${ }^{1}$
}

\begin{abstract}
Immunobiologic therapy is indicated for severe forms of psoriasis, resistant to conventional therapy. There is growing concern about their safety profile and possible association with cancer development. This article documents two cases of renal cell cancer during treatment with biologic therapy, reviewing what is described in the literature. The risk of solid tumors as a complication of using TNF-alpha inhibitors is controversial. No conclusion can be drawn from the data in the literature, however, we believe that special attention should be given to those with known risk factors for a specific neoplasm.
\end{abstract}

Keywords: Biological therapy; Kidney neoplasms; Psoriasis

Psoriasis is a chronic autoimmune disease that affects the skin and joints, with worldwide prevalence ranging from 0.8 to $4.6 \% .{ }^{1}$ A large number of topical and systemic treatments are available, and immunobiologic therapy is indicated for moderate to severe resistant forms, or individuals for whom conventional therapy is contraindicated. However, there is a growing concern about the safety profile, mainly due to the possible association of these drugs with an increased incidence of neoplasia. This article documents two cases of renal cell cancer during treatment with biologic therapy, reviewing the literature so far.

The first case concerns a 41-year-old man with eleven years of severe psoriasis and psoriatic arthritis (polyarticular and axial involvement). His level on the Psoriasis Area and Severity Index (PASI) remained at 28.9 despite taking methotrexate (MTX). Infliximab $4 \mathrm{mg} / \mathrm{kg}$ was thus added to existing therapy and he responded excellently. After a year of treatment, the calculated PASI was 1.8. At one hundred and eight weeks of infliximab, hepatitis was diagnosed due to the development of jaundice and elevated transaminase levels. An abdominal ultrasound was requested, which revealed a mass in the right kidney. After a urology evaluation, a total nephrectomy was performed with a diagnosis of clear cell renal carcinoma by histopathological analysis. The surgery was curative and administration of leflunomide $10 \mathrm{mg} /$ day stabilized joint symptoms and partially controlled the cutaneous lesions.

The following report concerns a 66 year-oldman with a 40-year history of psoriasis. He had already used MTX and was undergoing psoralen in addition to UVA light therapy (PUVA) treatment twice a week, and taking acitretin 30mg once a day. Despite the instituted therapy, new cutaneous lesions and joint symptoms appeared, leading consequently to the initiation of etanercept at a dose of $50 \mathrm{mg}$ per week. He achieved disease control with resolution of the joint symptoms and a decline in PASI of more than $90 \%$. After two hundred and eighteen weeks of therapy, prostatic symptoms led to an abdominal ultrasonography. In this case, a renal mass was also found and the patient underwent a total nephrectomy, whose histopathological examination revealed papillary renal carcinoma. Surgery was also curative, and the patient kept the disease under control with $30 \mathrm{mg} /$ day of acitretin.

Renal cell carcinoma accounts for 3\% of all malignancies, is twice as common in men and the age group 50-70 years is the most affected. ${ }^{2}$ The most common histologic type is clear cell carcinoma (75-85\%)

Received on 08.11.2013.

Approved by the Advisory Board and accepted for publication on 19.11.2013.

* Work performed at the Instituto de Dermatologia Prof. Rubem David Azulay- Santa Casa da Misericórdia do Rio de Janeiro (IDPRDA - SCMRJ) Rio de Janeiro (RJ), Brazil.

Conflict of interest: None

Financial funding: None

Instituto de Dermatologia Prof. Rubem David Azulay - Santa Casa da Misericórdia do Rio de Janeiro (IDPRDA - SCMRJ) - Rio de Janeiro (RJ), Brazil. 
followed by papillary (10-15\%), chromophobe (5$10 \%)$, oncocytic $(3-7 \%)$ and collecting duct $(<1 \%){ }^{3}$ Since it is a silent cancer, the increased availability and improvement of imaging methods have led to a large increase in the percentage of incidental renal tumors, with $50 \%$ classified as incidentalomas. ${ }^{4}$

Data on the risk of solid tumors as a complication of using TNFa (Tumor necrosis factor alpha) inhibitors are controversial. A study in Sweden with three cohorts found that the risk of solid malignancies in patients with rheumatoid arthritis treated with TNFa inhibitors is not greater than what would be expected with the disease alone. ${ }^{5}$ A meta-analysis of 63 studies, including a total of 29,423 patients, found no significant risk among those undergoing biologic therapy, compared with disease-modifying drugs or placebo, with a follow-up of at least 24 weeks. ${ }^{6}$ However, a double-blind, randomized study, showed increased risk of solid tumors in patients with Wegener's granulomatosis treated with TNFa inhibitors and cyclophosphamide, compared with those treated only with cyclophosphamide. ${ }^{7}$ Do TNFa inhibitors increase the chance of solid tumors, such as renal neoplasia? Or have they been overdiagnosed due to advances in imaging methods, leading to bias in studies?

In the specific case of renal cell carcinoma, few reports showed renal neoplasia in patients undergo-

\section{REFERENCES}

1. Naldi L. Epidemiology of psoriasis. Curr Drug Targets Inflamm Allergy. 2004:3:121-8.

2. Figlin RA. Renal cell carcinoma: management of advanced disease. J Urol. 1999;161:381-6.

3. Störkel S, van den Berg E. Morphological classification of renal cancer. World J Urol. 1995;13:153-8.

4. Landis SH, Murray T, Bolden S, Wingo PA. Cancer statistics, 1999. CA Cancer J Clin. 1999;49:8-31,1

5. Askling J, Fored CM, Brandt L, Baecklund E, Bertilsson L, Feltelius N, et al. Risks of solid cancers in patients with rheumatoid arthritis and after treatment with tumour necrosis factor antagonists. Ann Rheum Dis. 2005;64:1421-6.

6. Lopez-Olivo MA, Tayar JH, Martinez-Lopez JA, Pollono EN, Cueto JP, GonzalesCrespo MR, et al. Risk of Malignancies in Patients whith rheumathoid arthritis treated with biologic therapy: a meta-analysis. JAMA. 2012;308:898-908.

7. Stone JH, Holbrook JT, Marriott MA, Tibbs AK, Sejismundo LP, Min YI, et al.Solid Malignancies Among Patients in the Wegner's Granulomatosis Etanercept Trial. Arthritis Rheum. 2006;54:1608-18.

8. Harrison ML, Obermueller E, Maisey NR, Hoare S, Edmonds K, Li NF, et al .Tumor Necrosis Factor $\alpha$ as a new target for renal cell carcinoma: two sequential Phase Iltrials of Infliximab at standart and high dose. J Clin Oncol. 2007;25:4542-9.

9. Gelfand JM, Shin DB, Neimann AL, Wang X, Margolis DJ, Troxel AB. The risk of Iymphoma in patients with psoriasis. J Invest Dermatol. 2006;126:2194-201.

10. Brauchli YB, Jick SS, Miret M, Meier CR. Psoriasis and Risk of Incident Cancer: An Inception Cohort Study with a Nested Case-Control Analysis. J Invest Dermatol. 2009;129:2604-12. ing immunobiologic therapy. Some authors studied the benefit of TNFa inhibitors as an adjunctive therapy in treating these tumors, based on the fact that TNFa receptors were found in neoplasic renal cells. ${ }^{8}$ We have found evidence in the literature that patients with psoriasis have an increased incidence of lymphoproliferative disorders, particularly Hodgkin's lymphoma and cutaneous T-cell lymphoma. ${ }^{9}$ There is also a higher risk of solid tumors, and associated characteristics include the use of oral medication (gravity indicators) and long duration of disease ( $\geq 4$ years). ${ }^{10}$

TNFa inhibitors are associated with potentially serious adverse effects. However, these risks must be interpreted in the context of the potential benefits associated with such products.

The adverse effects of conventional treatments, including the risk of inducing malignancy, are also significant in most cases. Thus, the decision to use a TNF inhibitor should be individual, based on the specific clinical characteristics and specific risk profile of a particular patient.

With respect to the patients described above, we cannot draw conclusions from the data found in the literature regarding the development of renal cancer with the instituted therapy. However, we believe that special attention should be given to those with known risk factors for a specific neoplasm, who use these medications. $\square$

\author{
MAILING ADDRESS: \\ Fabiana Palmieri Zarur \\ Rua Guimarães Rosa 203 apto 705 - Barra da Tijuca \\ 22793-620 - Rio de Janeiro - RJ \\ Brazil \\ E-mail:fabianazarur@hotmail.com
}

How to cite this article: Zarur FP, d'Almeida LFV, Mafort M, Gusmão PR, Avelleira JCR. Two cases of renal cell cancer during immunobiologic therapy for psoriasis. An Bras Dermatol. 2014;89(6):1017-8. 